\title{
molecules
}

ISSN 1420-3049

www.mdpi.com/journal/molecules

Review

\section{Chiral Peptide Nucleic Acids with a Substituent in the $N$-(2-Aminoethy)glycine Backbone}

\section{Toru Sugiyama $^{1, *}$ and Atsushi Kittaka ${ }^{2}$}

1 Department of Life Sciences, Graduate School of Arts and Sciences, The University of Tokyo, Komaba, Meguro-ku, Tokyo 153-8902, Japan

2 Faculty of Pharmaceutical Sciences, Teikyo University, Kaga, Itabashi-ku, Tokyo 173-8605, Japan; E-Mail: akittaka@pharm.teikyo-u.ac.jp

* Author to whom correspondence should be addressed; E-Mail: csugi@mail.ecc.u-tokyo.ac.jp; Tel./Fax: +81-3-5465-8743.

Received: 14 December 2012; in revised form: 19 December 2012 / Accepted: 19 December 2012 / Published: 27 December 2012

\begin{abstract}
A peptide nucleic acid (PNA) is a synthetic nucleic acid mimic in which the sugar-phosphate backbone is replaced by a peptide backbone. PNAs hybridize to complementary DNA and RNA with higher affinity and superior sequence selectivity compared to DNA. PNAs are resistant to nucleases and proteases and have a low affinity for proteins. These properties make PNAs an attractive agent for biological and medical applications. To improve the antisense and antigene properties of PNAs, many backbone modifications of PNAs have been explored under the concept of preorganization. This review focuses on chiral PNAs bearing a substituent in the $\mathrm{N}$-(2-aminoethyl)glycine backbone. Syntheses, properties, and applications of chiral PNAs are described.
\end{abstract}

Keywords: peptide nucleic acid; chiral; preorganization; antigene

\section{Introduction}

A peptide nucleic acid (PNA) is a synthetic analogue of DNA first reported by Nielsen et al. in 1991 [1]. In PNA, the sugar-phosphate backbone of DNA is replaced by a peptide backbone consisting of $N$-(2-aminoethyl)glycine units. PNA oligomers hybridize to complementary sequences by WatsonCrick base pairing in spite of its structural difference from DNA [2-4]. Since the neutral peptide backbone of PNA does not have electrostatic repulsion that generally destabilizes DNA-DNA 
duplexes, thermal stability of PNA-DNA duplexes is higher than that of DNA-DNA duplexes. The relative rigidity of the PNA backbone improves sequence selectivity on hybridization. PNAs are resistant to nucleases and proteases [5] and have a low affinity for proteins [6]. A remarkable feature of PNAs is their ability to invade double-stranded DNA. Some reports suggest that PNAs can target duplex DNA even in living cells by strand invasion [7-11]. Strand invasion requires high stability of PNA-DNA duplexes to compete with the displaced DNA strand. To improve the antisense and antigene potency of PNAs, it is reasonable to increase binding affinity for DNA and RNA by suitable preorganization. An approach for improving DNA binding affinity is the design and synthesis of preorganized PNAs preferring a right-handed helical conformation. Reports have appeared demonstrating that preorganization can be achieved by cyclization of the PNA backbone or by adding substituents to the backbone [12,13]. In addition, original PNA has some drawbacks such as poor cellular uptake and relatively low solubility in aqueous media. The development of modified PNAs also aims to overcome these problems. In the present review, we intend to focus on chiral PNAs bearing substituents on the original $N$-(2-aminoethyl)glycine backbone and present them divided into three groups ( $\alpha$-PNA, $\beta$-PNA, and $\gamma$-PNA) based on the position of a substituent in the PNA backbone (Figure 1).

Figure 1. Chemical structures of DNA, PNA, and chiral $(\alpha-, \beta-, \gamma-)$ PNAs.

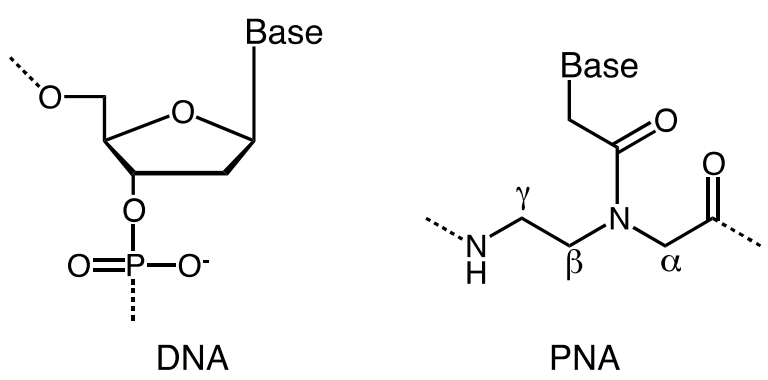<smiles>[R]C(C(C)=O)N(CCNC)C(=O)C[18O]</smiles>

$\alpha-P N A$<smiles>CNCC(P)N(CC(C)=O)C(=O)C[13C](=O)c1ccccc1</smiles>

$\beta-P N A$<smiles>[R8]CC(=O)N(CC(C)=O)CC([R])NC</smiles>

$\gamma$-PNA

\section{2. $\alpha-P N A$}

\subsection{Synthesis and Properties of $\alpha-P N A s$}

Nielsen et al. reported the first $\alpha$-chiral PNA in 1994, in which glycine moiety of the PNA backbone was substituted by alanine [14]. Both the L- and D-forms of the chiral monomers were synthesized from L- or D-alanine and incorporated into oligomers. Thermal stability of PNA-DNA duplex containing D-form monomers was similar to that of the original PNA with a glycine backbone, whereas a reduction was observed when L-form monomers were incorporated. Reductive amination is the most used procedure to obtain an $\alpha$-chiral aminoethyglycine backbone and a variety of $\alpha$-chiral 
PNAs bearing side chains from amino acids have been prepared by this method [15-17]. Alternatively, solid-phase synthesis of chiral monomers has been reported [18].

A critical problem in the synthesis of chiral $\alpha$-PNAs is racemization of $\alpha$-carbon during oligomer synthesis [19]. A systematic study of the optical purity of PNA oligomers as a function of the coupling conditions used in solid-phase synthesis revealed that DIC/HOBt gives the best result. Coupling with HATU or HBTU as a coupling agent resulted in relatively high levels of racemization. In particular, HATU gave rise to more rapid racemization [20]. Since HATU and HBTU are widely used in PNA synthesis, these results have to be taken into account. The optical purity of $\alpha$-PNA oligomers can be improved by omitting the preactivation step when using HATU.

Submonomer solid-phase synthesis has been reported as an alternative method for the synthesis of PNAs [21,22]. Sforza et al. developed a submonomeric approach to minimize the racemization of PNA during the solid-phase synthesis [23]. An orthogonally protected chiral submonomer (boxed in Scheme 1) was used for Boc-based solid-phase synthesis. A chiral PNA monomer unit was constructed by Fmoc deprotection of the submonomer and coupling with the carboxymethylnucleobase on resin (Scheme 1). This approach gives $\alpha$-PNA oligomers with the highest optical purity among reported methods.

Scheme 1. Submonomeric cycle for the insertion of a chiral monomer into a PNA chain on resin [23].

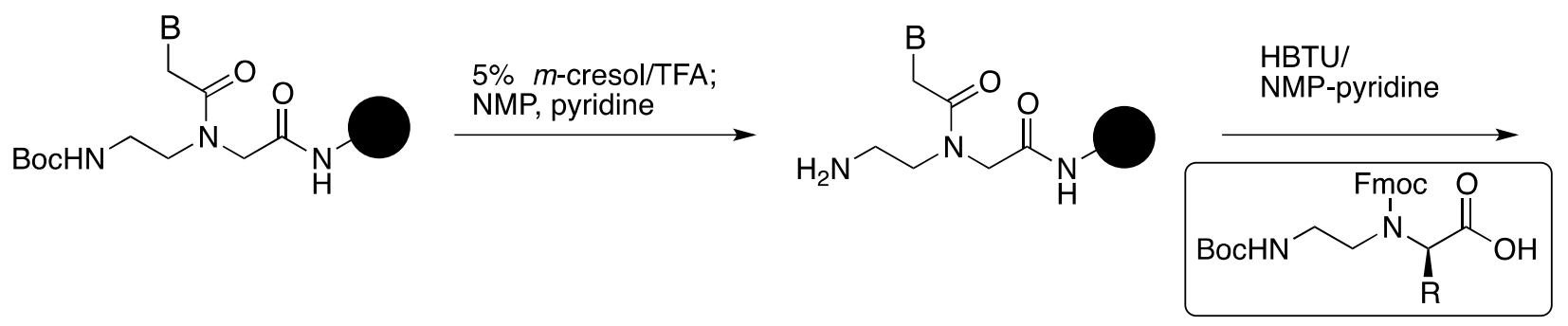

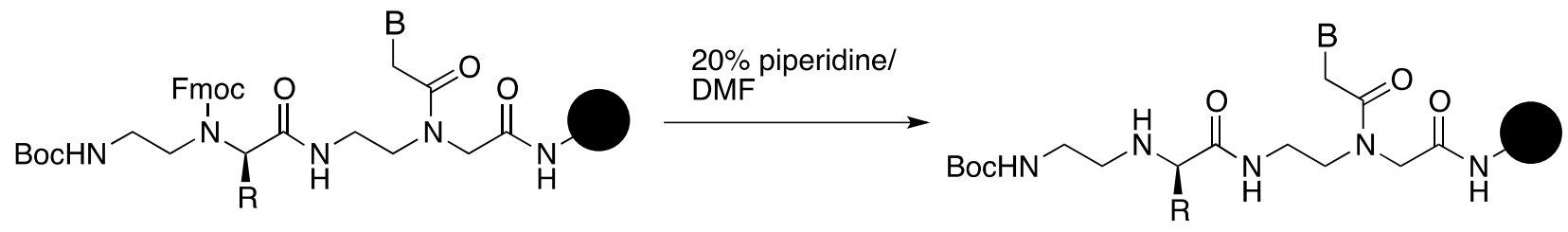

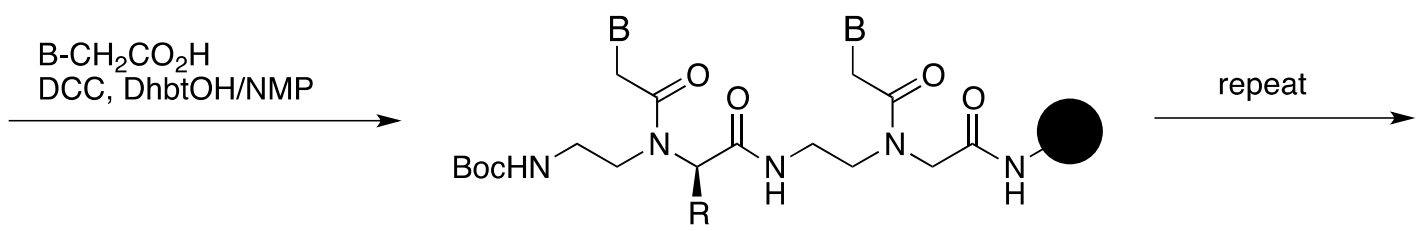

Introduction of a side chain at the $\alpha$-position caused moderate destabilization of PNA-DNA duplexes relative to the unmodified PNA [14-16,24]. The extent was larger for PNA oligomers carrying L-form monomers than for those carrying D-form monomers. In contrast, D-Lys-based PNA exhibited higher $T_{\mathrm{m}}$ than that of unmodified PNA. This was due to electrostatic attraction between the ammonium group of lysine side chain and the phosphate groups of DNA.

Incorporation of three consecutive D-Lys-based $\alpha$-PNA monomers greatly improved the sequence selectivity of PNA oligomer with moderate expense to DNA binding affinity (Table 1) [25] and the 
crystal structure of a PNA decamer containing three D-Lys-based monomers hybridized with its complementary DNA provided valuable insights into the PNA structure. Crystallographic data indicate that $\alpha$-PNAs prefer the P-helix conformation. The introduction of a chiral center at the $\alpha$-position of the PNA backbone limits the ability of the PNA strands to adopt other conformations, thus improving the mismatch discrimination ability [26].

Table 1. Melting temperatures $\left({ }^{\circ} \mathrm{C}\right)$ of D-lysine-based $\alpha$-PNA-DNA duplexes [25].

\begin{tabular}{|c|c|c|}
\hline PNA $^{a}$ & $\begin{array}{l}T_{\mathrm{m}}\left({ }^{\circ} \mathrm{C}\right) \\
\text { perfect match } \\
5^{\prime} \text {-AGTGATCTAC-3' }\end{array}$ & $\begin{array}{l}T_{\mathrm{m}}\left({ }^{\circ} \mathrm{C}\right) \\
\text { single mismatch } \\
5^{\prime} \text {-AGTG } \underline{\text { TCTAC-3' }}\end{array}$ \\
\hline H-GTAGATCACT-NH 2 & 50 & 40 \\
\hline H-GTAGATCACT-NH ${ }_{2}$ & 43 & - \\
\hline 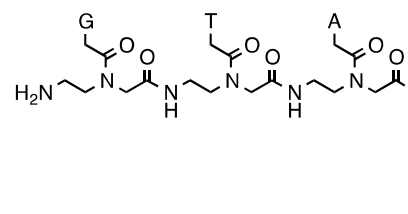 & $\mathrm{NH}_{3}^{+} \quad \mathrm{NH}_{3}^{+}$ & ${\stackrel{A}{Y} O_{O}}_{C_{Y} O_{O}}^{T} \underbrace{}_{Y}$ \\
\hline
\end{tabular}

${ }^{a}$ Bold letters indicate modified backbone units.

The lysine side chain of $\alpha$-Lys monomer was also used as a handle for site-specific incorporation of functional molecules into PNA oligomers. For example, Seitz et al. synthesized PNAs carrying FAM and TMR fluorophores in the middle of the PNA sequences (Figure 2A) [27].

D-arginine-based PNA is a special case (Table 2). Although the guanidinium group of $\alpha$-Arg PNA ( $\alpha$-GPNA) is positively charged under physiological $\mathrm{pH}$, incorporation of one unit of $\alpha$-GPNA into PNA decamer destabilized the PNA-DNA duplex; however, incorporation of multiple units of D-form $\alpha$-GPNAs at every other position improved DNA binding affinity. By spacing the arginine units, electrostatic attraction between the guanidinium groups and the phosphates seems to overcome the adverse effect of steric repulsion arising from arginine side chains themselves [28]. Recently, $\alpha$-GPNA was used for PNA microarray and its higher sequence selectivity has been demonstrated [29].

Table 2. Melting temperatures $\left({ }^{\circ} \mathrm{C}\right)$ of $\alpha$-GPNA-DNA duplexes $[28]^{\mathrm{a}}$.

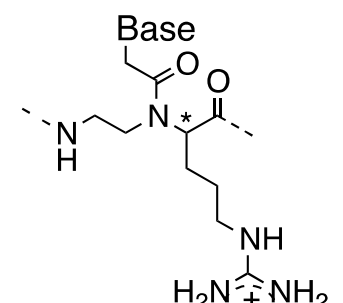

\begin{tabular}{|c|c|c|}
\hline Sequence & $T_{m}\left({ }^{\circ} \mathrm{C}\right)$ & $T_{m}$ \\
\hline H-GCATGTTTGA- ${ }^{\mathrm{L}} \mathrm{Lys}^{-\mathrm{NH}_{2}}$ & 43 & \\
\hline H-GCATG ${ }^{\mathrm{L}}$ TTTGA- $^{-}{ }^{\mathrm{L}} \mathrm{Lys}^{-\mathrm{NH}_{2}}$ & 39 & -4 \\
\hline H-GCATG ${ }^{\mathrm{D}}$ TTTGA- ${ }^{\mathrm{L}}$ Lys-NH${ }_{2}$ & 41 & -2 \\
\hline 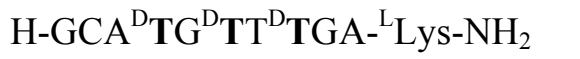 & 47 & +4 \\
\hline H-G ${ }^{\mathrm{D}} \mathbf{C} A^{\mathrm{D}} \mathbf{T} \mathrm{G}^{\mathrm{D}} \mathbf{T} \mathrm{T}^{\mathrm{D}} \mathbf{T} \mathrm{G}^{\mathrm{D}} \mathbf{A}-{ }^{\mathrm{L}}$ Lys-NH & 50 & +7 \\
\hline
\end{tabular}

${ }^{a}$ Bold letters indicate modified backbone units and superscripts ( $\mathrm{L}$ or $\mathrm{D}$ ) indicate the configuration of the amino acids from which the backbone units were derived.

As expected, the introduction of negatively charged side chains into the backbone destabilized PNA-DNA duplexes [15]. Moreover, PNAs derived from bulky amino acids, such as Tyr, His, Trp, Phe and Val, showed lower $T_{\mathrm{m}} \mathrm{s}$ due to steric hindrance [16]. 
Nielsen et al. reported the synthesis of a series of $\alpha$-PNAs bearing glycosylated side chains at the $\alpha$-position and demonstrated their selective biodistribution (Figure 2B) [30]. Metzler-Nolte et al. reported the synthesis of $C$-linked glycosylated $\alpha$-PNA and its successful incorporation into a PNA oligomer using Fmoc chemistry (Figure 2C) [31]. In addition to natural amino acids and carbohydrates, cyclobutyl-carbonyl-containing $\alpha$-PNA monomer has been stereoselectively synthesized from (+)- $\alpha$-pinene and its incorporation did not change the binding affinity of the PNA oligomer towards RNA, DNA or PNA with the complementary sequence (Figure 2D) [32]. Czerny et al. recently introduced phosphonic ester into the $\alpha$-side chain (pePNA) (Figure 2E). Its incorporation into standard PNA oligomers improved antisense potency compared to unmodified PNAs [33].

Figure 2. Structures of $\alpha$-PNAs bearing functional molecules [27,30-33].

(A)

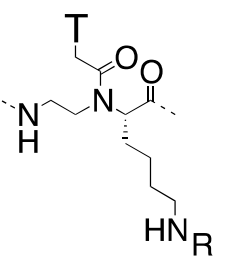

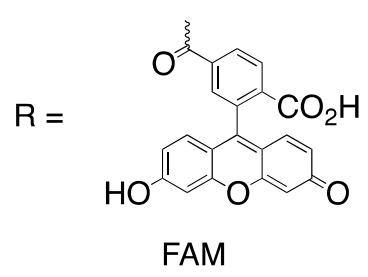

(C)<smiles>[3H]CC(=O)N(CN)CC(=O)OCC(=O)O</smiles>

(B)
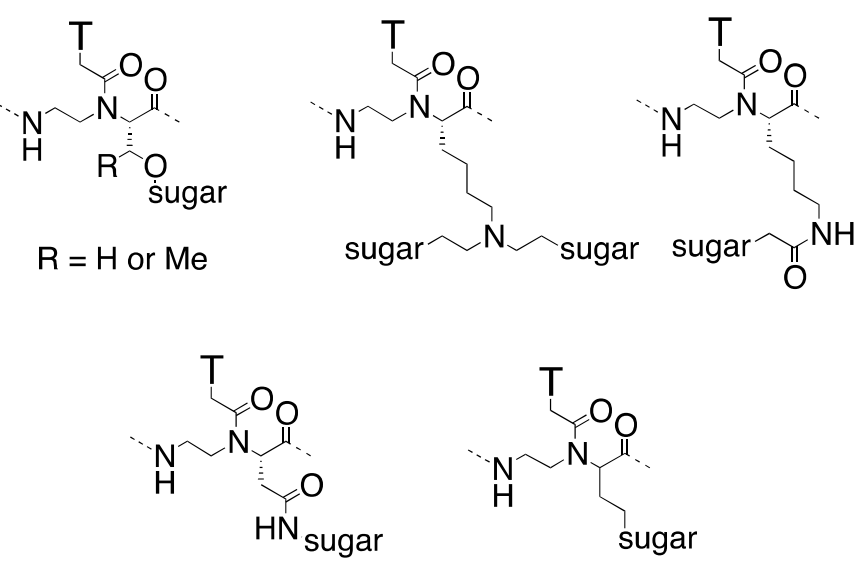

sugar $=\mathrm{D}$-galactose, L-fucose, $\mathrm{D}$-mannose

(D)

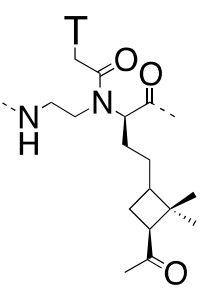

$(\mathrm{E})$

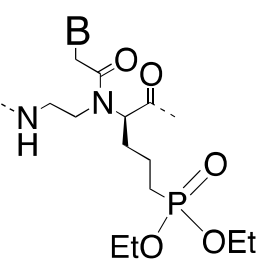

Armitage et al. used $\alpha$-PNAs as a tool for studying interactions between small molecules and the PNA-DNA duplex [34]. They synthesized PNA oligomers containing L- or D-leucine-based $\alpha$-PNA monomers (Figure 3) and compared the effect of $\alpha$-side chains on cyanine dye aggregation. Incorporation of L-luecine-based units significantly hindered cyanine dye aggregation, whereas the D-leucine analogue was less inhibitory. Since isobutyl groups project into the minor groove in the L-leucine-based duplex, effective blockage of the dye access suggests minor groove binding of the dye. The authors proposed a molecular recognition mechanism in which cyanine dyes assemble into helical aggregates by using the minor groove of a PNA-DNA duplex as a template. 
Figure 3. Structures of L- or D-leucine-based $\alpha$-PNAs [34].<smiles>CCCC(C(C)C)C(C(C)=O)N(CCNC)C(=O)Cn1cc(C)c(=O)[nH]c1=O</smiles>

directed into the minor groove<smiles>CCC[C@H](C(C)C)N(CCNC)C(=O)Cn1cc(C)c(=O)[nH]c1=O</smiles>

directed away from the minor groove

Although achiral, we would also like to mention $\alpha, \alpha$-disubstituted PNA (Figure 4). Recently, Ganesh et al. reported that the incorporation of gem-dimethyl substituted PNA monomers into PNA oligomers increases the $T_{\mathrm{m}}$ of PNA-DNA duplexes [35]. Interestingly, incorporation of the homologous aminopropyl-( $\alpha, \alpha$-dimethyl)glycyl (apdmg)-PNA monomers also improved DNA binding. It would be intriguing to compare this finding with alanine-based $\alpha$-PNA whose incorporation into the oligomer does not significantly change the thermal stability of PNA-DNA duplexes [14]. Introduction of appropriate rigidity without any chirality improved DNA binding properties of PNA. Another interesting feature of dimethyl PNAs is their preferential binding to DNA than to RNA.

Figure 4. Structures of $\alpha, \alpha$-dimethyl PNAs [35] and alanine-based $\alpha$-PNA.<smiles>[3H]CC(=O)N(CCNC)C(C)(C)C(C)=O</smiles>

aedmg-PNA<smiles>[3H]CC(=O)N(CCCNC)C(C)(C)C(C)=O</smiles>

apdmg-PNA<smiles>[3H]CC(=O)N(CCNC)C(C)C(C)=O</smiles>

$\alpha$-Ala PNA

\subsection{Double-Duplex Invasion}

Double-duplex invasion is a binding mode of PNA that targets both DNA strands simultaneously using pseudocomplementary PNA (pcPNA) pairs [36]. In pcPNA, adenine and thymine were replaced with 2,6-diaminopurine and 2-thiouracil, respectively (Figure 5A). The diaminopurine-thiouracil base pair is significantly destabilized because of steric hindrance, and thus, PNA-PNA duplex formed by pcPNA strands became unstable, while PNA-DNA duplexes retained high stability. The efficiency of double-duplex invasion was dependent on $\mathrm{A} / \mathrm{T}$ contents of target DNA sequences and the invasion did not proceed efficiently when $\mathrm{G} / \mathrm{C}$ rich sequences were targeted. In 2008, Komiyama et al. incorporated positive charges into pcPNA pairs by using $\alpha$-D-Lys PNA monomers (Figure 5B) [37]. In this system PNA-PNA duplex is further destabilized by additional electrostatic repulsion and, as a result, even G/C rich sequences could be targeted. Finally, this approach reduced the sequence requirement for efficient double-duplex invasion from $40 \% \mathrm{~A} / \mathrm{T}$ content to $20 \%$. 
Figure 5. (A) Pseudo-complementary bases 2,6-diaminopurine and 2-thiouracil used in pcPNA; (B) D-lysine-base $\alpha$-PNA; (C) Illustration of double-duplex invasion process of pcPNAs with additional positive charges. Electrostatic repulsion further destabilized the PNA-PNA duplex [36,37].

(A)

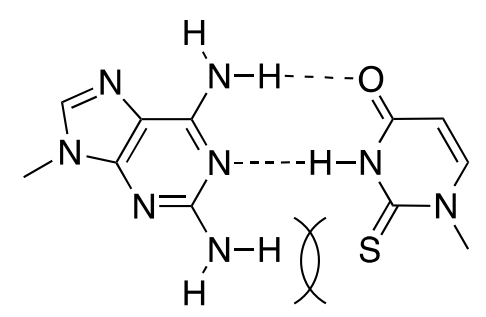

2,6-Diaminopurine

2-Thiouracil
(B)

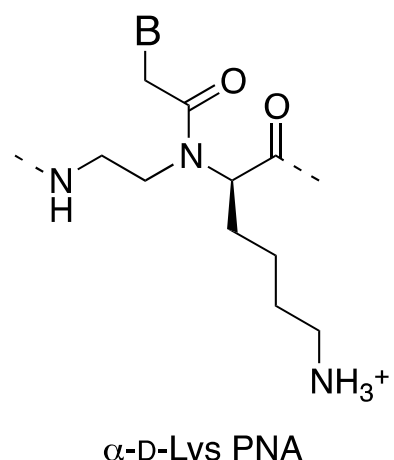

pcPNA with additional

positive charges

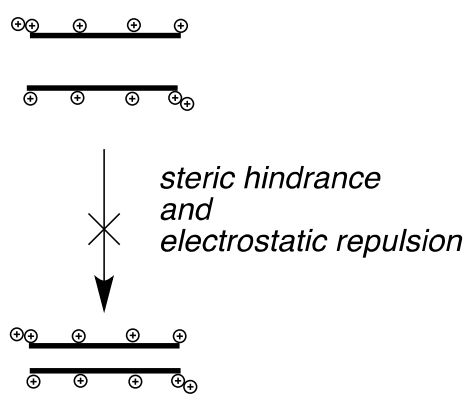

\subsection{Cellular Uptake of $\alpha-P N A s$}

Considered as an antisense or antigene agent, poor cellular uptake of PNA is a significant drawback and several methods have been developed to overcome this problem [38]. These include conjugation of PNAs to cell-penetrating peptides (CPPs) and chemical modification of the PNA backbone. PNA-peptide conjugates can be internalized into cells through endocytosis [39]. The major fraction of PNA localizes to endosomal compartments and is not available for DNA/RNA targeting. Thus, only a small fraction of PNA that escapes the endosome or is taken up by alternative pathways can exhibit biological activity. To promote the release of PNA-peptide conjugates from endosomes, additives such as calcium ions and chloroquin can be used; however, the potency of PNA-peptide conjugates was improved to only a small extent and these agents exhibited pronounced toxicity [40,41]. Moreover, a 14-mer PNA oligomer containing three units of D-Lys-based $\alpha$-PNA monomers and its peptide conjugates have been tested for cellular uptake and found to induce endocytotic uptake in most of the tested cell lines [42].

Ly et al. introduced a guanidinium group into the PNA backbone [43] based on the finding that the HIV-1 Tat transcription domain (GRKKRRQRRR) [44], arginine-rich peptides [45], and a homoarginine peptoid exhibited marked cellular uptake properties [46]. Cellular uptake of fully 
modified $\alpha$-GPNA decamer derived from L-arginine ( $\alpha$-L-GPNA in Figure 6 ) was evaluated with human HCT116 (colon) and Sao-2 (osteosarcoma) cell lines. $\alpha$-GPNA permeated the cell membrane and appeared to localize specifically in the nucleus. Since there was no difference in the uptake properties of $\alpha$-GPNA at $37{ }^{\circ} \mathrm{C}$ and $4{ }^{\circ} \mathrm{C}$, the uptake mechanism of $\alpha$-GPNA was neither endocytosisdriven nor receptor mediated. Membrane flipping has been proposed as a mechanism [43].

Figure 6. Structures of $\alpha$-L-GPNA [43] and $\alpha$-D-GPNA [47].
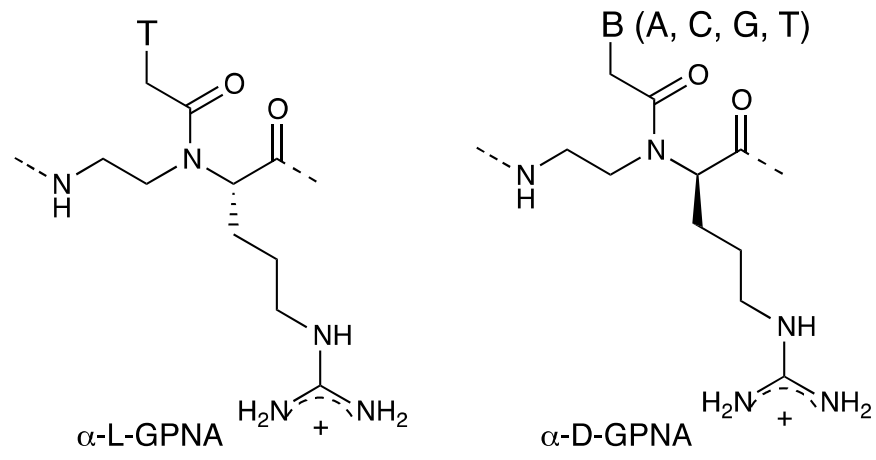

$\alpha$-GPNA oligomers in which unmodified PNA units and $\alpha$-GPNA units were alternated at every other position possessed optimal hybridization and cellular uptake properties. Cellular uptake of $\alpha$-GPNA octamer and dodecamer containing alternate backbone derived from D-arginine ( $\alpha$-D-GPNA in Figure 6) was also addressed and found to be efficient for HeLa and ES cells [47]. In contrast, neither the peptide containing the corresponding number of arginine residues $\left.(\mathrm{Fl} \text {-abu-RRRR-NH})_{2}\right)$ nor the standard achiral PNA octamer with an $\mathrm{N}$-terminal arginine tetramer (Fl-abu-RRRR-CGATCTGA$\mathrm{NH}_{2}$ ) was taken up by either cell type. Successful cellular uptake of $\alpha$-GPNA by ES cells is a particularly important finding because ES cells are extremely difficult to transduce, even when the best transfecting agents are used. The authors noticed that their results were consistent with a voltage-driven mechanism of arginine-rich peptides proposed by Wender et al. [48]; that is, positively charged guanidinium groups of arginine form bidentate hydrogen bonds with acceptor functionalities on the cell surface such as phospholipids. The resultant ion pair complexes migrate across the cell membrane driven by the difference in the membrane potential and then the peptide enters the cytosol. The same uptake mechanism has been supposed for $\alpha$-GPNA.

To further gain insight into the uptake properties, the intracellular distribution of a 18-mer, alternating $\alpha$-D-GPNA oligomer was examined [28]. The $\alpha$-GPNA was taken up by Hela cells and localized specifically to the endoplamic reticulum (ER) where mRNAs are translated into proteins. This ER-specific localization was distinct from shorter $\alpha$-GPNAs [47]. Since mRNAs are translated into proteins in ER, specific localization of $\alpha$-GPNA assured its promising potential as an antisense agent.

18-mer, $\alpha$-GPNAs with the same modification were applied to antisense inhibition of human E-cadherin gene expression [49]. Of the six $\alpha$-GPNA oligomers designed to target the E-cadherin gene transcript, the oligomer designed to bind to the transcription start-site was the most potent. This is consistent with the finding obtained through antisense experiments with achiral PNA oligomers [50]. It is noteworthy that $\alpha$-GPNAs were less toxic to the cells than the corresponding PNA-polyarginine conjugates. Even at concentrations $(10-15 \mu \mathrm{M})$ where more than $90 \%$ of the cells treated with the 
PNA-polyarginine conjugate underwent apoptosis, the $\alpha$-GPNA showed no noticeable sign of toxicity. It has been suggested that the cytotoxic effects of the PNA-peptide conjugates might be due to their amphipathic nature. The hydrophilic polyarginine domain of the conjugate interacts with the phospholipids on the cell surface, while the relatively hydrophobic PNA domain inserts into the lipid bilayers. As a result, the cell membrane may be perturbed, leading to cell death. Meanwhile, $\alpha$-GPNAs are less amphipathic and therefore less toxic to the cells.

\section{3. $\gamma$-PNA}

\subsection{Synthesis and Properties of $\gamma-P N A s$}

Although the first $\gamma$-chiral PNA monomer was reported in 1994 [51], oligomers carrying $\gamma$-chiral units did not appear until 2005 [52-55]. As in the case of $\alpha$-PNAs, most $\gamma$-chiral aminoethyglycine backbones were constructed by using reductive amination as a key step (Scheme 2A). Optically active aminoaldehydes are prepared from $\mathrm{N}, \mathrm{O}$-dimethylhydroxyl amide derivatives of the corresponding amino acids by reduction with $\mathrm{LiAlH}_{4}$. Reductive amination of the aldehyde with a glycine ester gave the $\gamma$-modified PNA backbone; however, these aldehydes required cautious treatment because they were prone to racemization [56,57]. Using this procedure, various $\gamma$-PNA monomers were synthesized, including Ala, Ser, Lys and Cys-based PNAs. In addition, the submonomeric approach that was originally developed for the synthesis of $\alpha$-PNA was also adopted for $\gamma$-PNAs [52].

Scheme 2. Synthesis of $\gamma$-PNA monomer by (A) reductive amination $[51,53,54,58,59]$ or by (B) Mitsunobu-Fukuyama reaction as a key step [60,61].

(A)
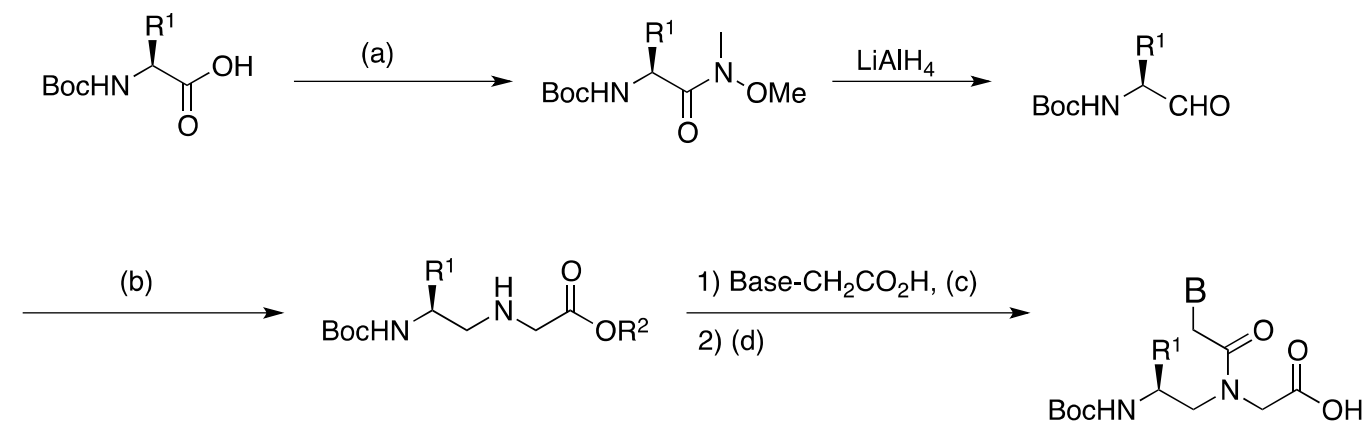

\begin{tabular}{llll}
$\mathrm{R}^{1}$ & $\mathrm{R}^{2}$ & \multicolumn{1}{c}{$\mathrm{c}$} & \multicolumn{1}{c}{$\mathrm{b}$} \\
\hline $\mathrm{Me}$ & $\mathrm{Me}$ & iBuO-CO-Cl,NMM, MeHNOMe & $\mathrm{H}_{2} \mathrm{NCH}_{2} \mathrm{CO}_{2} \mathrm{Me}, \mathrm{NaBH}_{3} \mathrm{CN}$ \\
$\mathrm{BnOCH}{ }_{2}$ & $\mathrm{Et}$ & iBuO-CO-Cl,NMM, MeHNOMe & $\mathrm{H}_{2} \mathrm{NCH}_{2} \mathrm{CO}_{2} \mathrm{Et}, \mathrm{NaBH}_{3} \mathrm{CN}, \mathrm{AcOH}$ \\
$\mathrm{FmocHN}\left(\mathrm{CH}_{2}\right)_{4}$ & $\mathrm{Bn}$ & EDC, MeHNOMe & $\mathrm{H}_{2} \mathrm{NCH}_{2} \mathrm{CO}_{2} \mathrm{Bn}, \mathrm{NaBH}(\mathrm{OAc})_{3}$ \\
Trt-S & $\mathrm{Me}$ & iBuO-CO-Cl,NMM, MeHNOMe & $\mathrm{H}_{2} \mathrm{NCH}_{2} \mathrm{CO}_{2} \mathrm{Me}, \mathrm{NaBH}_{3} \mathrm{CN}$ \\
PMBS & $\mathrm{Et}$ & DIC, MeHNOMe & $\mathrm{H}_{2} \mathrm{NCH}_{2} \mathrm{CO}_{2} \mathrm{Et}, \mathrm{NaBH} \mathrm{NaN}_{3} \mathrm{AcOH}$ \\
\hline
\end{tabular}

\begin{tabular}{lll}
\multicolumn{1}{c}{$\mathrm{c}$} & $\mathrm{d}$ & ref \\
\hline iBuO-CO-Cl, NMM & $\mathrm{NaOH}$ & 51 \\
DCC, DhbtOH & $\mathrm{LiOH}$ & 58 \\
EDC, $\mathrm{HOBt}$ & $\mathrm{H}_{2}, 10 \% \mathrm{Pd} / \mathrm{C}$ & 53 \\
PvCl, NMM & $\mathrm{LiOH}$ & 54 \\
EDC & $\mathrm{LiOH}$ & 59 \\
\hline
\end{tabular}


Scheme 2. Cont.

(B)

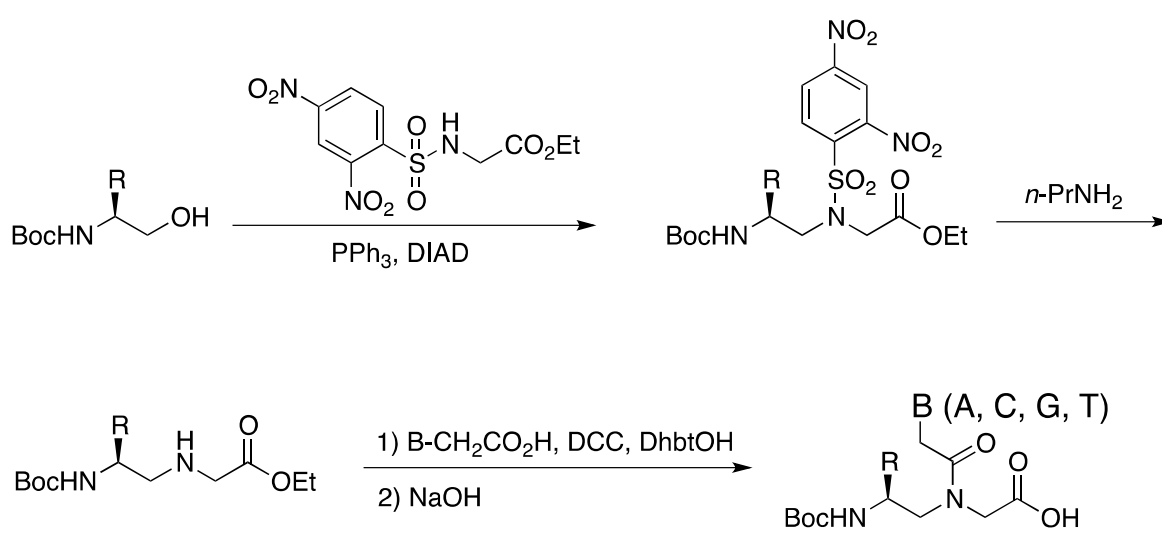

Some $\gamma$-PNA monomers were prepared by the Mitsunobu-Fukuyama reaction (Scheme 2B) [60-62]. This procedure used an aminoalcohol as the key intermediate instead of the aminoaldehyde described above. Since the $\alpha$-proton of aminoalcohol was inert to deprotonation by the base, enantiomerically pure monomers could be obtained. Mitsunobu-Fukuyama coupling of protected aminoalcohol with 2-(2,4-dinitrophenylsulfonamido)acetate proceeded without the risk of racemization. Removal of the dinitrosulfonate protecting group with a mild base yielded a chiral $\gamma$-PNA backbone. DCC-mediated coupling with the carboxymethylnucleobases and hydrolysis of the esters gave the $\gamma$-PNA monomers.

Winssinger et al. reported a protecting group combination $(\mathrm{Mtt} / \mathrm{Boc})$ that was orthogonal to Fmoc-based solid-phase PNA synthesis (Scheme 3) [63]. This protocol was developed for PNA-encoded diversity-oriented synthesis, and they synthesized serine-based $\gamma$-PNA monomers with these protecting groups. Amine protection of serine amide derived from Fmoc-Ser $(t \mathrm{Bu})-\mathrm{OH}$ and subsequent reduction with $\mathrm{LiAlH}_{4}$ afforded Mtt-protected diamine. Alkylation, acylation and hydrolysis gave $\gamma$-PNA monomers protected with Mtt/Boc combination.

Scheme 3. Synthesis of $\gamma$-PNA monomers with Mtt/Boc protecting group combination [63].<smiles>CC(C)(C)OC[C@H](NC(F)F)C(=O)O</smiles>
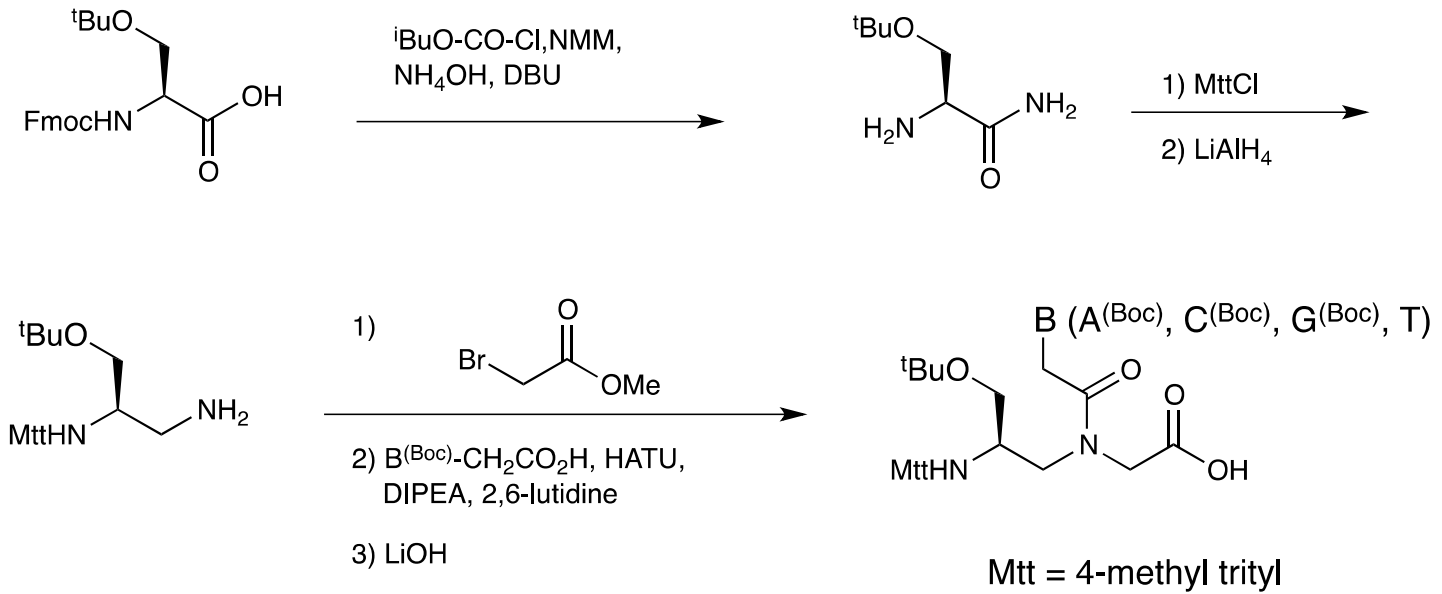

Figure 7 shows the structures of some representative $\gamma$-PNAs. In 2005, Appella et al. reported PNA oligomers carrying $\gamma$-Lys PNA as a handle for fluorene incorporation aiming at developing quencherfree molecular PNA beacons [53]. Incorporation of $\gamma$-modified PNA slightly stabilized PNA-DNA duplexes relative to the unmodified duplex. Moreover, the ability of $\gamma$-PNA to discriminate single-base 
mismatches was superior to that of the corresponding unmodified PNA. In the subsequent paper [64], the authors demonstrated that $\gamma$-Lys PNA was a versatile scaffold to attach various functional molecules including peptides and fluorophores. UV melting experiments revealed that $\gamma$-L-Lys PNA monomer stabilized PNA-DNA duplex, whereas $\gamma$-D-Lys PNA monomer markedly destabilized the duplex (Table 3). Recently the authors have applied $\gamma$-L-Lys PNAs to multivalent display of integrin ligands in a controlled manner [65]. Cysteine-base $\gamma$-PNAs heve been also reported [54,59]. PNA oligomers carrying the Cys-based monomer at the $N$-terminus could be used for native chemical PNA ligation with thioesters of PNAs to yield long chain PNAs. Previous to the report of $\gamma$-Lys PNA, $\gamma$-Cys PNA was used for the conjugation of functional molecules and such conjugates were used for multivalent scaffold assembly [66]. Marchelli et al. compared the thermal stability of $\alpha$-Lys PNAs with $\gamma$-Lys PNAs and revealed that $\gamma$-modification was more effective to improve the DNA binding ability. Moreover, the effect of stereochemistry on DNA binding was more evident in $\gamma$-PNA than $\alpha$-PNA [52,67]. Romanelli et al. reported $\gamma$-PNA bearing a sulfate group aimed at making PNAs more DNA-like in terms of polarity and charge. Three sulfate monomers were incorporated into homopyrimidine PNA nonamer (CTCCTCCTC, in the sequence all Ts were replaced with sulphate T). $\mathrm{PNA}_{2} \bullet \mathrm{DNA}$ triplex formed by sulfate-modified PNA was less stable $\left(\Delta T_{\mathrm{m}}-5.6{ }^{\circ} \mathrm{C}\right)$ than the standard PNA hybrid. This destabilization was explained by electrostatic repulsion between the negatively charged phosphate of DNA and sulphate of the modified PNA. The modified PNA could be lipofected into human breast cancer (SKB3) cells due to its negative charge and exhibited antigene activity against ErbB2 gene [68].

Figure 7. Structures of $\gamma$-PNAs [51-54,64,67,68].<smiles>[3H]CC(=O)N(CC(=O)O)C[C@@H](C)NC(=O)O</smiles>

1994 Liang et al.<smiles>[R]C(CN(C(=O)C[B])C([R])C(C)=O)NC</smiles>

$\mathrm{R}=\mathrm{H}$ or $\left(\mathrm{CH}_{2}\right)_{4} \mathrm{NH}_{2}$ $\mathrm{R}^{\prime}=\mathrm{H}$ or $\left(\mathrm{CH}_{2}\right)_{4} \mathrm{NH}_{2}$ 2005 Marchelli et al.

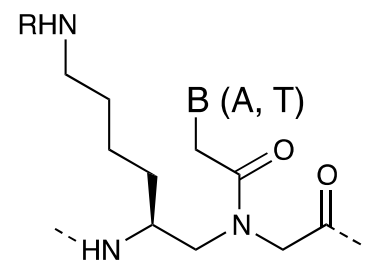

2005 Appella et al.<smiles></smiles>

2006 Ly et al.<smiles>CCCC(=O)N(CC(C)=O)C[C@H](CS)NC</smiles>

2005 Seitz et al. $(\mathrm{B}=\mathrm{A})$ 2006 Filippov et al. $(\mathrm{B}=\mathrm{T})$<smiles>CN[C@@H](COS(=O)(=O)O)CC(=O)N(CC(C)=O)CC(C)=O</smiles>

2012 Romanelli et al.

Detailed spectroscopic studies of serine- or alanine-based $\gamma$-PNAs carried out by Ly et al. revealed that a simple $\gamma$-backbone modification preorganized single-stranded PNA oligomers into a right-handed helical structure that was very similar to that of PNA-DNA duplex. The $\gamma$-PNAs bound to DNA with very high affinity and high sequence selectivity. Helical induction was sterically driven and stabilized 
by base stacking. The fully $\gamma$-modified decameric PNA formed exceptionally stable PNA-DNA duplex with an increase of $19{ }^{\circ} \mathrm{C}$ of the $T_{\mathrm{m}}$ compared to the unmodified PNA [58]. The author's group also reported the crystal structure of a PNA-DNA duplex with complete $\gamma$-backbone modification. The structure illustrates that $\gamma$-PNA possesses conformational flexibility while maintaining sufficient structural integrity to adopt the P-helical conformation on hybridization with DNA [69]. It is noteworthy that $\gamma$-PNAs in the single-strand state (determined by NMR) and in the hybrid duplex state (determined by X-ray crystallography) adopt a very similar conformation.

Ly et al. have reported a variety of $\gamma$-PNAs bearing side chains derived from amino acids [70]. It was demonstrated that the $\gamma$-position could accommodate various hindered side chains without inducing adverse effects on the hybridization properties of PNAs (Table 3). This is in contrast to $\alpha$-PNA, which is sensitive to steric hindrance arising from side chains at the $\alpha$-position. Introduction of each chiral unit into the oligomer resulted in an increase in the $T_{\mathrm{m}}$ of the PNA-DNA duplex by $\sim 4{ }^{\circ} \mathrm{C}[52,62,68,70]$.

Table 3. Melting temperatures $\left({ }^{\circ} \mathrm{C}\right)$ of $\gamma$-PNA-DNA duplexes.

\begin{tabular}{llll}
\hline Backbone & $\boldsymbol{T}_{\boldsymbol{m}}\left({ }^{\circ} \mathbf{C}\right)$ & PNA sequence & Reference \\
\cline { 2 - 4 } Modification & & & \\
\hline Gly & 47 & $\mathrm{a}$ & {$[70]$} \\
L-Ala & 51 & $\mathrm{a}$ & \\
L-Val & 51 & $\mathrm{a}$ & \\
L-Ile & 51 & $\mathrm{a}$ & \\
L-Phe & 51 & $\mathrm{a}$ & {$[68]$} \\
\hline Gly & 44 & $\mathrm{a}$ & \\
L-Ser & 48 & $\mathrm{a}$ & {$[62]$} \\
\hline Gly & 49.7 & $\mathrm{~b}$ & \\
L-Lys & 51.4 & $\mathrm{~b}$ & {$[52]$} \\
D-Lys & 36.4 & $\mathrm{~b}$ & \\
\hline Gly & 50 & $\mathrm{c}$ & \\
L-Lys & 56 & $\mathrm{c}$ & \\
D-Lys & 32 & $\mathrm{C}$ & \\
\hline
\end{tabular}

The PNA sequence is (a) H-GCATGTTTGA- ${ }^{\mathrm{L}} \mathrm{Lys}_{\mathrm{N} H}$, (b) H-GTAGATCACT- ${ }^{\mathrm{L}} \mathrm{Lys}_{\mathrm{N}} \mathrm{NH}_{2}$, or (c) H-GTAGATCACT- $\mathrm{NH}_{2}$. The backbone at the $\mathbf{T}$ position was constructed with the monomer derived from the indicated amino acid.

\subsection{Duplex Invasion of $\gamma-P N A s$}

One of the most remarkable properties of PNA is their ability to recognize some sequences within duplex DNA by strand invasion. Strand invasion proceeds by three distinct mechanisms depending on the DNA target and the PNA sequence: triplex invasion [1], double-duplex invasion [36], and duplex invasion [71-74]. DNA targets for triplex invasion are basically limited to homopurine sequences. Double-duplex invasion mode can target a wider range of sequences than triplex invasion, still limited to AT-rich sequences. In principle, simple duplex invasion mode does not have sequence limitations; however, duplex invasion complexes are much less stable than the others. As a result, duplex invasion proceeds only when targeting topologically constrained supercoiled plasmid DNA [72] or transcription 
start sites that offer a single-stranded region [11]. To target any site within the human genome, new mixed-sequence PNAs that can invade canonical B-form duplex DNA need to be developed. $\gamma$-PNA appears to fulfill this purpose. Ly et al. have reported that mixed-sequence L-alanine-based $\gamma$-PNA decamers can invade linear duplex B-form DNA with the assistance of terminal acridine or modified nucleobase (G-clamp) (Figure 8, Table 4) [75,76]. Although strand invasion is usually performed under low salt conditions, incorporation of G-clamp nucleobases enabled invasion even at physiological ionic strength [77]. Moreover, $\gamma$-PNAs with a length of 15-20 nucleotides could invade duplex DNA without the need to attach any ancillary agents to PNAs [78]. Recently, MiniPEG-containing $\gamma$-PNA was reported that possessed further improved DNA binding properties by eliminating nonspecific binding (Figure 9) [60,79].

Figure 8. (A) Illustration of duplex invasion process of $\gamma$-PNA; (B) Structures of L-alanine-based $\gamma$-PNA, acridine-linked L-lysine residue, and G-clamp-G base pair [75-78].

(A)

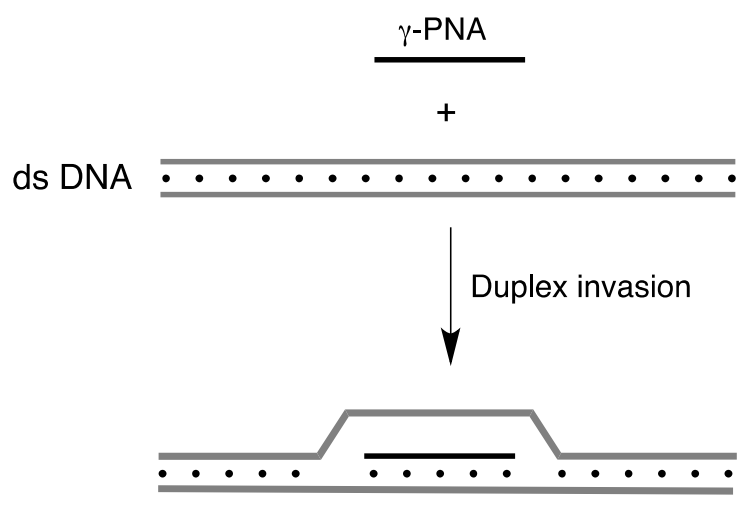

(B)<smiles>CN[C@@H](CCCCNc1c2ccccc2nc2ccccc12)C(=O)CN(CC(C)=O)C(=O)C[13CH3]</smiles>

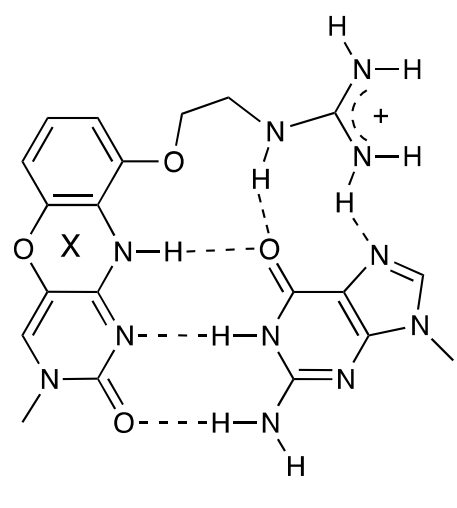

G-clamp Guanine 
Table 4. $\gamma$-PNA oligomers used for duplex invasion $[75-78]^{\text {a }}$.

\begin{tabular}{|c|c|c|c|}
\hline PNA sequences & $T_{\mathrm{m}}\left({ }^{\circ} \mathrm{C}\right)$ & Duplex invasion & Reference \\
\hline PNA1: $\mathrm{H}^{-}{ }^{\mathrm{L}}$ Lys-GACCACAGAT- ${ }^{\mathrm{L}} \mathrm{Lys}-\mathrm{NH}_{2}$ & 59 & - & [75] \\
\hline PNA2: $\mathrm{H}^{-}{ }^{\mathrm{L}}$ Lys-GACCACAGAT- ${ }^{\mathrm{L}} \mathrm{Lys}^{-} \mathrm{NH}_{2}$ & $\sim 90$ & - & \\
\hline PNA3: $\mathrm{H}-{ }^{\mathrm{L}}$ Lys-GACCACAGAT $-{ }^{\mathrm{L}} \mathrm{Lys}(\mathrm{Acr})-{ }^{\mathrm{L}} \mathrm{Lys}-\mathrm{NH}_{2}$ & $\sim 90$ & + & \\
\hline PNA4: $\mathrm{H}^{\mathrm{L}}{ }^{\mathrm{L}}$ Lys-GAXCACAGAT- ${ }^{\mathrm{L}} \mathrm{Lys}^{-} \mathrm{NH}_{2}$ & n.d. & + & {$[76,77]$} \\
\hline PNA5: $\mathrm{H}^{\mathrm{L}}{ }^{\mathrm{L}}$ Lys-GAXCAXAGAT- ${ }^{\mathrm{L}} \mathrm{Lys}-\mathrm{NH}_{2}$ & n.d. & + & \\
\hline PNA6: $\mathrm{H}^{-}{ }^{\mathrm{L}}$ Lys-GAXXAXAGAT- ${ }^{\mathrm{L}} \mathrm{Lys}^{-} \mathrm{NH}_{2}$ & n.d. & + & \\
\hline PNA7: $\mathrm{H}^{-}{ }^{\mathrm{L}}$ Lys-GACCACAGATCTAAG- ${ }^{-}{ }^{\mathrm{L}}{ }^{\mathrm{Lys}}-\mathrm{NH}_{2}$ & $>95$ & + & {$[78]$} \\
\hline PNA8: $\mathrm{H}^{-}{ }^{\mathrm{L}} \mathrm{Lys}-$ TATGAGACCACAGATCTAAG- ${ }^{\mathrm{L}} \mathrm{Lys}-\mathrm{NH}_{2}$ & $>95$ & + & \\
\hline
\end{tabular}

${ }^{\text {a }}$ Bold letters indicate $\gamma$-modified backbone units. $\mathbf{X}$ is G-clamp. n.d.: not determined.

Figure 9. Structure of $\gamma$-MiniPEG PNA $[60,79]$.

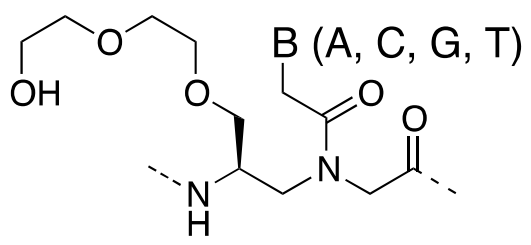

\subsection{Cell Internalization of $\gamma-P N A s$ and Related Modified PNAs}

As described in Section 2.2, the ability of $\alpha$-GPNAs to traverse the cell membrane, and bind to target RNAs in living cells without significant toxicity made them promising agents for antisense applications; however, the high cost associated with monomer synthesis hampered large-scale preparation for clinical testing. Ly et al. have reported the synthesis of $\gamma$-GPNA, the second-generation GPNA, which was prepared from inexpensive Boc-L-Lysine (selected based purely on cost) and had a homo-arginine side chain at the $\gamma$-position (Figure 10A) [59]. Stabilization of PNA-DNA duplexes by incorporation of $\gamma$-GPNA units was significant compared to $\alpha$-GPNAs. Alternate backbone spacing was more effective to enhance thermal stability than the consecutive arrangement. The authors attributed the enhancement of thermal stability to conformational preorganization, not to electrostatic interactions between guanidinium and phosphate groups because of the lack of salt dependence of $\Delta T_{\mathrm{m}}$. A fully alternate $\gamma$-GPNA decamer was taken up by HeLa cells and the uptake efficiency was comparable to that of the TAT transduction domain. As in the case of $\alpha$-GPNAs, $\gamma$-GPNAs localized in the ER. The authors attributed the improved cellular uptake of $\gamma$-GPNA to their helical conformation.

Recently, inhibition of micro-RNA by GPNAs has been reported by Manicardi et al. [80]. Anti-miR-210 activity of PNAs in leukemic K562 cells was examined using a series of 18-mer PNAs: unmodified PNAs, PNAs conjugated with arginine octamer and modified PNAs containing eight units of $\alpha$ - or $\gamma$-GPNA monomers. $\gamma$-GPNA used by this group carried an arginine side chain (Figure 10B). Two types of placement of GPNA monomers in the sequence were used: alternate spacing and consecutive placement of GPNA units at the $N$-terminus. All modified PNAs were efficiently internalized and the fluorescence of the labeled PNAs was mainly cytoplasmatic. It is noteworthy that uptake of $\alpha$-GPNAs was resistant to serum. The best anti-miR-210 activity was exhibited by $\gamma$-GPNA with consecutive placement. The authors pointed out that overall anti-miR activity of GPNAs is a 
combination of cellular uptake and RNA binding. The substituents in the PNA backbone play a role not only in cellular uptake, but also in the mechanism of miR recognition and inactivation.

Figure 10. Structures of $\gamma$-GPNAs $[59,80]$.

(A)

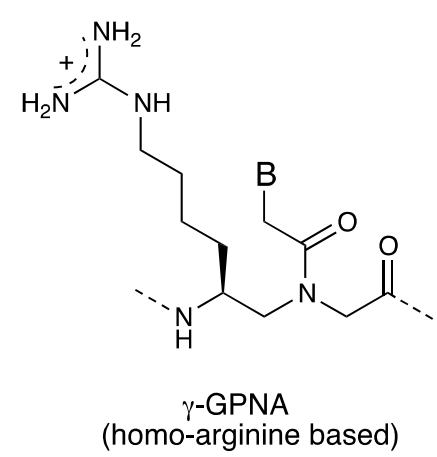

(B)

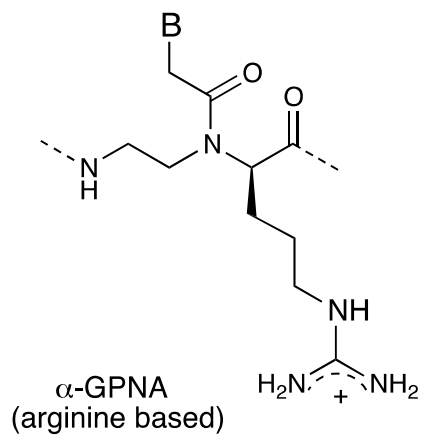

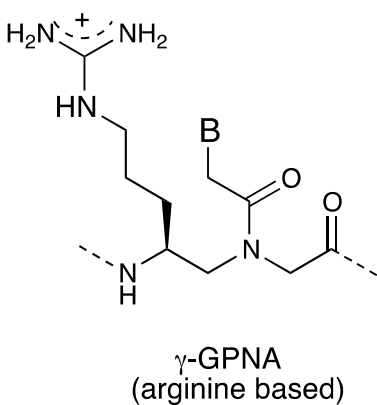

They also compared the DNA binding affinity and sequence selectivity of the PNA containing three adjacent $\alpha$-GPNA monomers with those of the corresponding $\gamma$-GPNA [81]. The $\gamma$-GPNA exhibited higher $T_{\mathrm{m}}$, whereas $\alpha$-GPNA exhibited higher sequence selectivity. The difference in sequence selectivity between $\alpha$-GPNA and $\gamma$-GPNA was ascribed to the position of the side chains. The side chain in the $\alpha$-GPNA monomer was attached to the more rigid glycine moiety of the PNA backbone, whereas that of the $\gamma$-GPNA monomer was placed in the more flexible aminoethyl moiety. This rigidity may enhance steric repulsion between the side chains when hybridized with mismatched DNA.

The same group reported modified PNA with a nuclear localization signal (NLS) sequence embedded in the PNA backbone (Figure 11) [82]. The PNA was synthesized by a submonomeric strategy and its cellular uptake by rhabdomyosarcoma cells (RH30 cells) was investigated. Both the modified PNA and the NLS peptide were internalized into RH30 cells and localized to the nuclei, whereas unmodified PNA was not detected in the nuclei. It is known that the NLS peptide is transported to the nuclei by an importin-mediated mechanism. Based on the similarity of the localization patterns, it was assumed that the modified PNA could interact with importin. Although PNA was originally developed as a nucleic acid mimic, the authors intend to explore its potential as a peptide mimic.

Figure 11. Structure of the modified PNA containing the embedded NLS sequence [82].

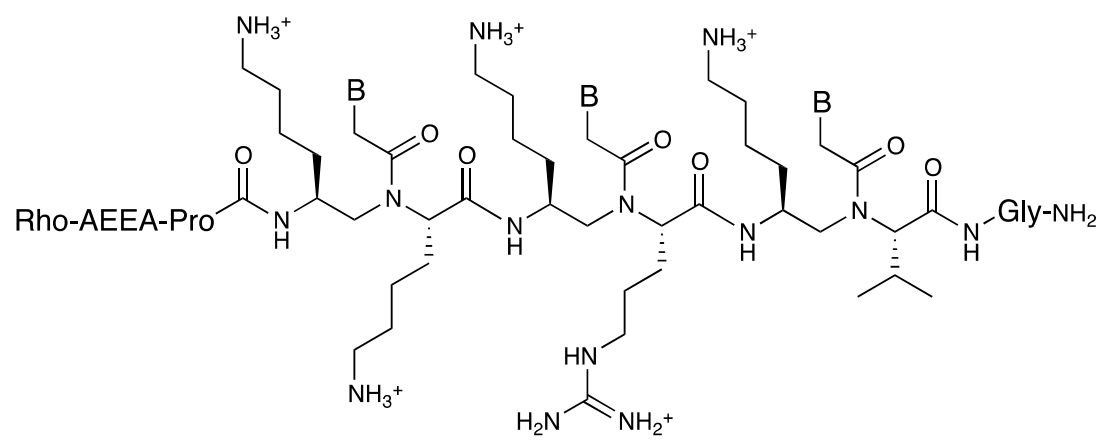

Ganesh et al. reported the synthesis of chiral PNAs (am-PNAs) with cationic aminomethyl groups at the $\alpha$ - or $\gamma$-position of the PNA backbone (Figure 12) [83,84]. The am-PNAs formed more stable PNA-DNA duplexes than the unmodified PNA and the order of stabilization was $\gamma-(S)-a m$ 
PNA $>\alpha-(R)$-am PNA $>\alpha-(S)$-am PNA. The am-PNAs could traverse the cell membrane of HeLa cells and localized into the nucleus. The order of cellular uptake efficiency of am-PNAs was again $\gamma-(S)>\alpha-(R)>\alpha-(S)$.

Figure 12. Structures of aminomethyl-PNAs $[83,84]$.

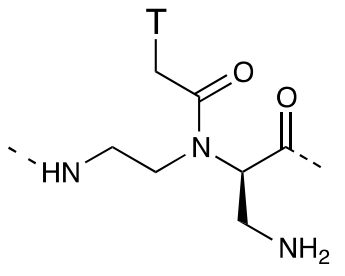

$\alpha-(R)-a m$ PNA<smiles>[3H]CC(=O)N(CCNC)[C@@H](CN)C(C)=O</smiles>

$\alpha-(S)-a m$ PNA<smiles>[3H]CC(=O)N(CC(C)=O)C[C@H](CN)NC</smiles>

$\gamma-(S)$-am PNA

\section{4. $\beta$-PNA}

Although some cyclic PNA analogues contain a chiral center at the $\beta$-position [85-92], PNAs with a single substituent only at the $\beta$-position ( $\beta$-PNAs) have not been synthesized until recently. In 2011 , Sugiyama et al. reported the first $\beta$-PNA bearing a methyl group at the $\beta$-position [93]. Since the $\beta$-position of the PNA backbone corresponds to the C4' of the deoxyribose moiety of DNA and the C4' is a chiral carbon atom, the incorporation of a substituent at the $\beta$-position was expected to significantly affect the conformation and the DNA binding properties of PNA oligomers.

A PNA monomer possessing a methyl group at the $\beta$-position was designed and both enantiomers, $\beta-(S)$ - and $\beta-(R)$-configurations, were prepared. Scheme 4 illustrates the synthesis of $\beta-(S)$ thymine monomer. Using $\mathrm{CbzOPh},(S)$-1,2-diaminopropane derived from L-alanine was selectively mono-protected on the primary group located on the primary carbon atom in the presence of the primary amino group located on the secondary carbon. Although the requisite compound was obtained as the major isomer (major isomer: minor isomer $=92: 8$ ), it could not be separated from the minor isomer by the usual chromatographic methods. Thus, the mixture was directly subjected to alkylation with excess methyl bromoacetate. The minor isomer was completely dialkylated under the reaction condition and became chromatographically separable and thus, the Z-protected $\beta$-methyl PNA backbone was obtained. Coupling of the thymin-1-ylacetic acid was accomplished with EDCI. Alkaline hydrolysis, catalytic hydrogenation, and subsequent Fmoc protection with FmocOSu gave the $N$-Fmoc-protected $\beta$-PNA monomer. The corresponding enantiomer was also prepared from $(R)$-1,2-diaminopropane.

$\beta$-PNA containing three $S$-form chiral units (derived from L-alanine) and unmodified PNA showed similar $T_{\mathrm{m}}$ values (Table 5). In contrast, the enantiomer $\beta$-PNA carrying three $R$-form units (derived from D-alanine) did not bind to DNA. Thus, the stereochemistry of the $\beta$-carbon of the PNA backbone was critical to the hybridization ability of PNA and strictly limited to $S$-configuration. This contrasts to $\alpha$-PNAs in which stereochemistry of the $\alpha$-carbon arising from a methyl group hardly affected the DNA binding ability. 
Scheme 4. Synthesis of $\beta-(S)$-Methyl PNA thymine monomer [93].
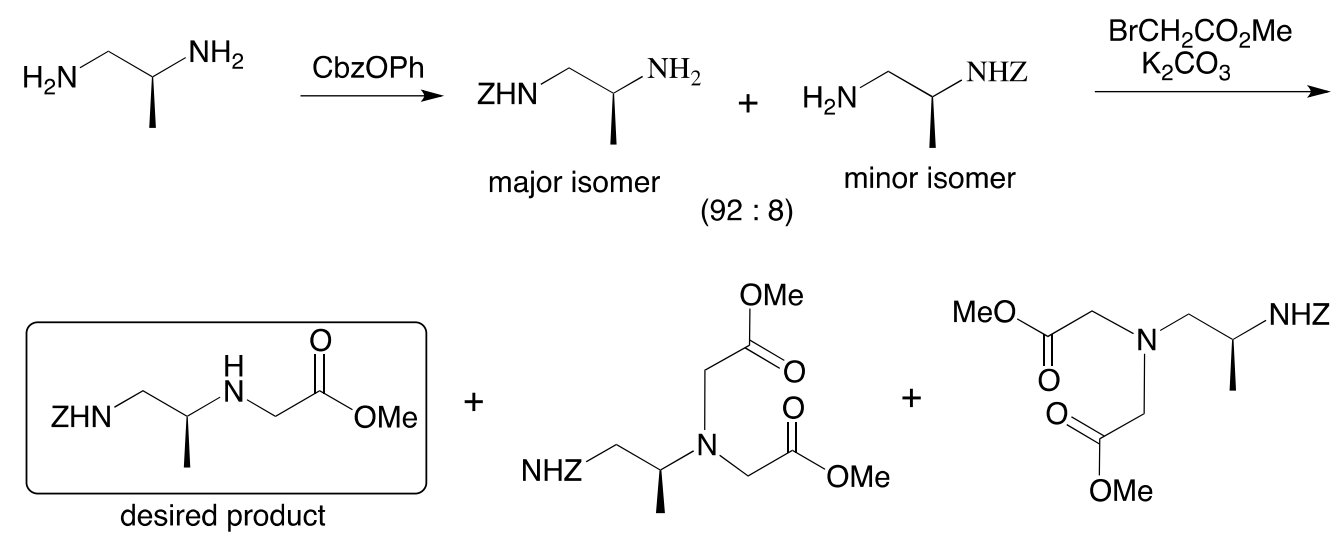

column chromatography

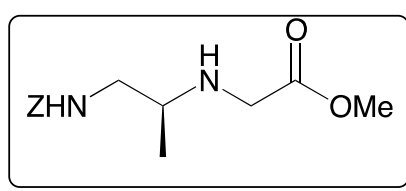

$\mathrm{T}-\mathrm{CH}_{2} \mathrm{CO}_{2} \mathrm{H}$

$\mathrm{EDCl}$<smiles>[Z7]CC(C)N(CC(=O)OC)C(=O)C[3H]</smiles>

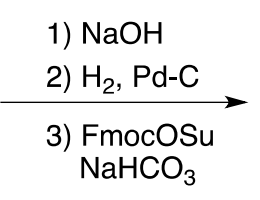<smiles>[3H]CC(=O)N(CC(=O)O)C(C)CNC(F)F</smiles>

$\beta-(S)$ Thymine monomer

Table 5. Melting temperatures $\left({ }^{\circ} \mathrm{C}\right)$ of $\beta$-PNA-DNA duplexes [93] ${ }^{\mathrm{a}}$.

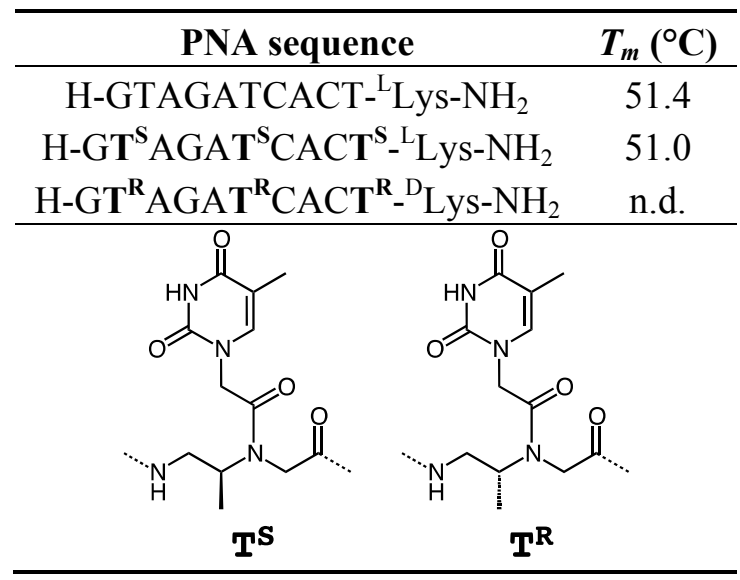

\footnotetext{
${ }^{\mathrm{a}}$ Bold letters indicate modified backbone units.
}

The circular dichroism (CD) spectra of $\beta$-PNAs indicated that $\beta-(S)$-PNA adopted a right-handed helical structure and $\beta-(R)$-PNA was left-handed; however, the induced right-handed structure of $\beta-(S)$ PNA did not contribute to the total PNA-DNA duplex stability. The benefit of the induced structure might be abolished by unfavorable steric interactions arising from $\beta$-methyl groups in the PNA-DNA hybrid duplex. Since the development of $\beta$-PNA is a new, unexplored field, more sophisticated designs may be possible. 


\section{Conclusions}

The great potential of PNA has stimulated chemists to develop new PNA analogues with superior properties to unmodified PNA. A large number of modified PNAs have been obtained by modifying the PNA backbone, nucleobases, and the linker connecting a nucleobase to the backbone. As described in this review, introduction of a substituent to the PNA backbone is a simple strategy but has proved fruitful in improving DNA binding properties and the sequence selectivity of PNAs. $\gamma$-PNAs seem to be the most potent in terms of DNA/RNA binding affinity. GPNAs provide a solution for the problem of poor cellular uptake of unmodified PNA. The accurate control of intracellular localization of PNAs will be the next challenge.

The synthetic protocol of modified PNAs with a substituent on the backbone is straightforward and therefore the cost of large-scale synthesis is within an acceptable range. Sufficient quantities of various modified PNAs will be available for biological investigations and animal experiments in the near future. Considering the application of PNAs for therapeutic purposes, issues such as metabolic pathways, pharmacokinetics and pharmacodynamics need to be taken into account.

\section{Acknowledgments}

This work was supported by Grants-in-Aid for Scientific Research (KAKENHI, No. 20590099 and 24590135 to T.S. and No. 24590021 to A.K.) from the Japan Society for the Promotion of Science.

\section{References}

1. Nielsen, P.E.; Egholm, M.; Berg, R.H.; Buchardt, O. Sequence-selective recognition of DNA by strand displacement with a thymine-substituted polyamide. Science 1991, 254, 1497-1500.

2. Egholm, M.; Buchardt, O.; Christensen, L.; Behrens, C.; Freier, S.M.; Driver, D.A.; Berg, R.H.; Kim, S.K.; Norden, B.; Nielsen, P.E. PNA hybridizes to complementary oligonucleotides obeying the Watson-Crick hydrogen-bonding rules. Nature 1993, 365, 566-568.

3. Jensen, K.K.; Orum, H.; Nielsen, P.E.; Norden, B. Kinetics for hybridization of peptide nucleic acids (PNA) with DNA and RNA studied with the BIAcore technique. Biochemistry 1997, 36, 5072-5077.

4. Ratilainen, T.; Holmen, A.; Tuite, E.; Nielsen, P.E.; Norden, B. Thermodynamics of sequencespecific binding of PNA to DNA. Biochemistry 2000, 39, 7781-7791.

5. Demidov, V.V.; Potaman, V.N.; Frank-Kamenetskii, M.D.; Egholm, M.; Buchardt, O.; Sonnichsen, S.H.; Nielsen, P.E. Stability of peptide nucleic acids in human serum and cellular extracts. Biochem. Pharmacol. 1994, 48, 1310-1313.

6. Hamilton, S.E.; Iyer, M.; Norton, J.C.; Corey, D.R. Specific and nonspecific inhibition of transcription by DNA, PNA, and phosphorothioate promoter analog duplexes. Bioorg. Med. Chem. Lett. 1996, 6, 2897-2900.

7. Cutrona, G.; Carpaneto, E.M.; Ulivi, M.; Roncella, S.; Landt, O.; Ferrarini, M.; Boffa, L.C. Effects in live cells of a c-myc anti-gene PNA linked to a nuclear localization signal. Nat. Biotechnol. 2000, 18, 300-303. 
8. Boffa, L.C.; Cutrona, G.; Cilli, M.; Mati, S.; Damonte, G.; Mariani, M.R.; Millo, E.; Moroni, M.; Roncella, S.; Fedeli, F.; Ferrarini, M. Inhibition of Burkitt's lymphoma cells growth in SCID mice by a PNA specific for a regulatory sequence of the translocated c-myc. Cancer Gene Ther. 2007, 14, 220-226.

9. Tonelli, R.; Purgato, S.; Camerin, C.; Fronza, R.; Bologna, F.; Alboresi, S.; Franzoni, M.; Corradini, R.; Sforza, S.; Faccini, A.; Shohet, J.M.; Marchelli, R.; Pession, A. Antigene peptide nucleic acid specifically inhibits $M Y C N$ expression in human neuroblastoma cells leading to cell growth inhibition and apoptosis. Mol. Cancer Ther. 2005, 4, 779-786.

10. Cogoi, S.; Codognotto, A.; Rapozzi, V.; Meeuwenoord, N.; van der Marel, G.; Xodo, L.E. Transcription inhibition of oncogenic $K R A S$ by a mutation-selective peptide nucleic acid conjugated to the PKKKRKV nuclear localization signal peptide. Biochemistry 2005, 44, 10510-10519.

11. Janowski, B.A.; Kaihatsu, K.; Huffman, K.E.; Schwartz, J.C.; Ram, R.; Hardy, D.; Mendelson, C.R.; Corey, D.R. Inhibiting transcription of chromosomal DNA with antigene peptide nucleic acids. Nat. Chem. Biol. 2005, 1, 210-215.

12. Kumar, V.A.; Ganesh, K.N. Conformationally constrained PNA analogues: Structural evolution toward DNA/RNA binding selectivity. Acc. Chem. Res. 2005, 38, 404-412.

13. Corradini, R.; Sforza, S.; Tedeschi, T.; Totsingan, F.; Manicardi, A.; Marchelli, R. Peptide nucleic acids with a structurally biased backbone. Updated review and emerging challenges. Curr. Top. Med. Chem. 2011, 11, 1535-1554.

14. Dueholm, K.L.; Petersen, K.H.; Jensen, D.K.; Egholm, M.; Nielsen, P.E.; Buchardt, O. Peptide nucleic acid (PNA) with a chiral backbone based on alanine. Bioorg. Med. Chem. Lett. 1994, 4, 1077-1080.

15. Haaima, G.; Lohse, A.; Buchardt, O.; Nielsen, P.E. Peptide nucleic acids (PNAs) containing thymine monomers derived from chiral amino acids: Hybridization and solubility properties of D-lysine PNA. Angew. Chem. Int. Ed. Engl. 1996, 35, 1939-1942.

16. Püschl, A.; Sforza, S.; Haaima, G.; Dahl, O.; Nielsen, P.E. Peptide nucleic acids (PNAs) with a functional backbone. Tetrahedron Lett. 1998, 39, 4707-4710.

17. Gupta, P.; Muse, O.; Rozners, E. Recognition of double-stranded RNA by guanidine-modified peptide nucleic acids. Biochemistry 2012, 51, 63-73.

18. Balaji, B.S.; Gallazzi, F.; Jia, F.; Lewis, M.R. An efficient, convenient solid-phase synthesis of amino acid-modified peptide nucleic acid monomers and oligomers. Bioconjug. Chem. 2006, 17, 551-558.

19. Corradini, R.; Sforza, S.; Dossena, A.; Palla, G.; Rocchi, R.; Filira, F.; Nastri, F.; Marchelli, R. Epimerization of peptide nucleic acids analogs during solid-phase synthesis: optimization of the coupling conditions for increasing the optical purity. J. Chem. Soc. Perkin Trans. 1 2001, 2690-2696.

20. Tedeschi, T.; Corradini, R.; Marchelli, R.; Pushl, A.; Nielsen, P.E. Racemization of chiral PNAs during solid-phase synthesis: Effect of the coupling conditions on enantiomeric purity. Tetrahedron: Asymmetry 2002, 13, 1629-1636.

21. Richter, L.S.; Zuckermann, R.N. Synthesis of peptide nucleic acids (PNA) by submonomer solid-phase synthesis. Bioorg. Med. Chem. Lett. 1995, 5, 1159-1163.

22. Viirre, R.D.; Hudson, R.H.E. Optimization of a solid-phase synthesis of a PNA monomer. Org. Lett. 2001, 3, 3931-3934. 
23. Sforza, S.; Tedeschi, T.; Corradini, R.; Ciavardelli, D.; Dossena, A.; Marchelli, R. Fast, solid-phase synthesis of chiral peptide nucleic acids with a high optical purity by a submonomeric strategy. Eur. J. Org. Chem. 2003, 2003, 1056-1063.

24. Sforza, S.; Haaima, G.; Marchelli, R.; Nielsen, P.E. Chiral peptide nucleic acids (PNAs): Helix handedness and DNA recognition. Eur. J. Org. Chem. 1999, 1999, 197-204.

25. Sforza, S.; Corradini, R.; Ghirardi, S.; Dossena, A.; Marchelli, R. DNA binding of a D-lysinebased chiral PNA: Direction control and mismatch recognition. Eur. J. Org. Chem. 2000, 2000, 2905-2913.

26. Menchise, V.; de Simone, G.; Tedeschi, T.; Corradini, R.; Sforza, S.; Marchelli, R.; Capasso, D.; Saviano, M.; Pedone, C. Insights into peptide nucleic acid (PNA) structural features: The crystal structure of a D-lysine-based chiral PNA-DNA duplex. Proc. Natl. Acad. Sci. USA 2003, 100, 12021-12026.

27. Dose, C.; Seitz, O. Single nucleotide specific detection of DNA by native chemical ligation of fluorescence labeled PNA-probes. Bioorg. Med. Chem. 2008, 16, 65-77.

28. Zhou, P.; Dragulescu-Andrasi, A.; Bhattacharya, B.; O’Keefe, H.; Vatta, P.; Hyldig-Nielsen, J.J.; Ly, D.H. Synthesis of cell-permeable peptide nucleic acids and characterization of their hybridization and uptake properties. Bioorg. Med. Chem. Lett. 2006, 16, 4931-4935.

29. Rossi, S.; Calabretta, A.; Tedeschi, T.; Sforza, S.; Arcioni, S.; Baldoni, L.; Corradini, R.; Marchelli, R. Selective recognition of DNA from olive leaves and olive oil by PNA and modified-PNA microarrays. Artificial DNA PNA XNA 2012, 3, 63-72.

30. Hamzavi, R.; Dolle, F.; Tavitian, B.; Dahl, O.; Nielsen, P.E. Modulation of the pharmacokinetic properties of PNA: Preparation of galactosyl, mannosyl, fucosyl, $N$-acetylgalactosaminyl, and $\mathrm{N}$-acetylglucosaminyl derivatives of aminoethylglycine peptide nucleic acid monomers and their incorporation into PNA oligomers. Bioconjug. Chem. 2003, 14, 941-954.

31. Hamzavi, R.; Meyer, C.; Metzler-Nolte, N. Synthesis of a C-linked glycosylated thymine-based PNA monomer and its incorporation into a PNA oligomer. Org. Biomol. Chem. 2005, 4, 3648-3651.

32. Aguado, G.P.; Rúa, F.; Branchadell, V.; Nielsen, P.E.; Ortuño, R.M. Cyclobutyl-carbonyl substituted PNA: Synthesis and study of a novel PNA derivative. Tetrahedron: Asymmetry 2006, 17, 2499-2503.

33. Dorn, S.; Aghaallaei, N.; Jung, G.; Bajoghli, B.; Werner, B.; Bock, H.; Lindhorst, T.; Czerny, T. Side chain modified peptide nucleic acids (PNA) for knock-down of six3 in medaka embryos. BMC Biotechnol. 2012, 12, doi:10.1186/1472-6750-12-50.

34. Dilek, I.; Madrid, M.; Singh, R.; Urrea, C.P.; Armitage, B.A. Effect of PNA backbone modifications on cyanine dye binding to PNA-DNA duplexes investigated by optical spectroscopy and molecular dynamics simulations. J. Am. Chem. Soc. 2005, 127, 3339-3345.

35. Gourishankar, A.; Ganesh, K.N. ( $\alpha, \alpha$-dimethyl)glycyl (dmg) PNAs. Achiral PNA analogs that form stronger hybrids with cDNA relative to isosequential RNA. Artificial DNA PNA XNA 2012, 3, 5-13.

36. Lohse, J.; Dahl, O.; Nielsen, P.E. Double duplex invasion by peptide nucleic acid: A general principle for sequence-specific targeting of double-stranded DNA. Proc. Natl. Acad. Sci. USA 1999, 96, 11804-11808. 
37. Ishizuka, T.; Yoshida, J.; Yamamoto, Y.; Sumaoka, J.; Tedeschi, T.; Corradini, R.; Sforza, S.; Komiyama, M. Chiral introduction of positive charges to PNA for double-duplex invasion to versatile sequences. Nucleic Acids Res. 2008, 36, 1464-1471.

38. Koppelhus, U.; Nielsen, P.E. Cellular delivery of peptide nucleic acid (PNA). Adv. Drug Deliv. Rev. 2003, 55, 267-280.

39. Nielsen, P.E. Addressing the challenges of cellular delivery and bioavailability of peptide nucleic acids (PNA). Q. Rev. Biophys. 2005, 38, 345-350.

40. Shiraishi, T.; Pankratova, S.; Nielsen, P.E. Calcium ions effectively enhance the effect of antisense peptide nucleic acids conjugated to cationic Tat and oligoarginine Peptides. Chem. Biol. 2005, 12, 923-929.

41. Hu, J.; Corey, D.R. Inhibiting gene expression with peptide nucleic acid (PNA)-peptide conjugates that target chromosomal DNA. Biochemistry 2007, 46, 7581-7589.

42. Koppelhus, U.; Awasthi, S.K.; Zachar, V.; Holst, H.U.; Ebbesen, P.; Nielsen, P.E. Cell-dependent differential cellular uptake of PNA, peptides, and PNA-peptide conjugates. Antisense Nucleic Acid Drug Dev. 2002, 12, 51-63.

43. Zhou, P.; Wang, M.; Du, L.; Fisher, G.W.; Waggoner, A.; Ly, D.H. Novel binding and efficient cellular uptake of guanidine-based peptide nucleic acids (GPNA). J. Am. Chem. Soc. 2003, 125, 6878-6879.

44. Nagahara, H.; Vocero-Akbini, A.M.; Snyder, E.L.; Ho, A.; Latham, D.G.; Lissy, N.A.; Becker-Hapak, M.; Ezhevsky, S.; Dowdy, S.F. Transduction of full-length TAT fusion proteins into mammalian cells: TAT-p27 $7^{\text {Kip1 }}$ induces cell migration. Nat. Med. 1998, 4, 1449-1452.

45. Futaki, S.; Suzuki, T.; Ohashi, W.; Yagami, T.; Tanaka, S.; Ueda, K.; Sugiura, Y. Arginine-rich peptides. J. Biol. Chem. 2001, 276, 5836-5840.

46. Wender, P.A.; Mitchell, D.J.; Pattabiraman, K.; Pelkey, E.T.; Steinman, L.; Rothbard, J.B. The design, synthesis, and evaluation of molecules that enable or enhance cellular uptake: Peptoid molecular transporters. Proc. Natl. Acad. Sci. USA 2000, 97, 13003-13008.

47. Dragulescu-Andrasi, A.; Zhou, P.; He, G.; Ly, D.H. Cell-permeable GPNA with appropriate backbone stereochemistry and spacing binds sequence-specifically to RNA. Chem. Commun. 2005, 41, 244-246.

48. Rothbard, J.B.; Jessop, T.C.; Lewis, R.S.; Murray, B.A.; Wender, P.A. Role of membrane potential and hydrogen bonding in the mechanism of translocation of guanidinium-rich peptides into cells. J. Am. Chem. Soc. 2004, 126, 9506-9507.

49. Dragulescu-Andrasi, A.; Rapireddy, S.; He, G.; Bhattacharya, B.; Hyldig-Nielsen, J.J.; Zon, G.; Ly, D.H. Cell-permeable peptide nucleic acid designed to bind to the 5'-untranslated region of E-cadherin transcript induces potent and sequence-specific antisense effects. J. Am. Chem. Soc. 2006, 128, 16104-16112.

50. Doyle, D.F.; Braasch, D.A.; Simmons, C.G.; Janowski, B.A.; Corey, D.R. Inhibition of gene expression inside cells by peptide nucleic acids: effect of mRNA target sequence, mismatched bases, and PNA length. Biochemistry 2001, 40, 53-64.

51. Kosynkina, L.; Wang, W.; Liang, T.C. A Convenient synthesis of chiral peptide nucleic acid (PNA) monomers. Tetrahedron Lett. 1994, 35, 5173-5176. 
52. Tedeschi, T.; Sforza, S.; Corradini, R.; Marchelli, R. Synthesis of new chiral PNAs bearing a dipeptide-mimic monomer with two lysine-derived stereogenic centres. Tetrahedron Lett. 2005, 46, 8395-8399.

53. Englund, E.A.; Appella, D.H. Synthesis of $\gamma$-substituted peptide nucleic acids: A new place to attach fluorophores without affecting DNA binding. Org. Lett. 2005, 7, 3465-3467.

54. Dose, C.; Seitz, O. Convergent Synthesis of Peptide Nucleic Acids by Native Chemical Ligation. Org. Lett. 2005, 7, 4365-4368.

55. Ficht, S.; Dose, C.; Seitz, O. As fast and selective as enzymatic ligations: Unpaired nucleobases increase the selectivity of DNA-controlled native chemical PNA ligation. ChemBioChem 2005, 6, 2098-2103.

56. Stanfield, C.F.; Parker, J.E.; Kanellis, P. Preparation of protected amino aldehydes. J. Org. Chem. 1981, 46, 4797-4798.

57. Rittle, K.E.; Homnick, C.F.; Ponticello, G.S.; Evans, B.E. A synthesis of statine utilizing an oxidative route to chiral $\alpha$-amino aldehydes. J. Org. Chem. 1982, 47, 3016-3018.

58. Dragulescu-Andrasi, A.; Rapireddy, S.; Frezza, B.M.; Gayathri, C.; Gil, R.R.; Ly, D.H. A simple $\gamma$-backbone modification preorganizes peptide nucleic acid into a helical structure. J. Am. Chem. Soc. 2006, 128, 10258-10267.

59. De Koning, M.C.; Petersen, L.; Weterings, J.J.; Overhand, M.; van der Marel, G.A.; Filippov, D.V. Synthesis of thiol-modified peptide nucleic acids designed for post-assembly conjugation reactions. Tetrahedron 2006, 62, 3248-3258.

60. Sahu, B.; Chenna, V.; Lathrop, K.L.; Thomas, S.M.; Zon, G.; Livak, K.J.; Ly, D.H. Synthesis of conformationally preorganized and cell-permeable guanidine-based $\gamma$-peptide nucleic acids ( $\gamma$ GPNAs). J. Org. Chem. 2009, 74, 1509-1516.

61. Sahu, B.; Sacui, I.; Rapireddy, S.; Zanotti, K.J.; Bahal, R.; Armitage, B.A.; Ly, D.H. Synthesis and characterization of conformationally preorganized, $(R)$-diethylene glycol-containing $\gamma$-peptide nucleic acids with superior hybridization properties and water solubility. J. Org. Chem. 2011, 76, 5614-5627.

62. Falkiewicz, B.; Kolodziejczyk, A.S.; Liberek, B.; Wisniewski, K. Synthesis of achiral and chiral peptide nucleic acid (PNA) monomers using Mitsunobu reaction. Tetrahedron 2001, 57, 7909-7917.

63. Chouikhi, D.; Ciobanu, M.; Zambaldo, C.; Duplan, V.; Barluenga, S.; Winssinger, N. Expanding the scope of PNA-encoded synthesis (PES): Mtt-protected PNA fully orthogonal to fmoc chemistry and a broad array of robust diversity-generating reactions. Chem. Eur. J. 2012, 18, 12698-12704.

64. Englund, E.A.; Appella, D.H. $\gamma$-Substituted peptide nucleic acids constructed from L-lysine are a versatile scaffold for multifunctional display. Angew. Chem. Int. Ed. 2007, 46, 1414-1418.

65. Englund, E.A.; Wang, D.; Fujigaki, H.; Sakai, H.; Micklitsch, C.M.; Ghirlando, R.; Martin-Manso, G.; Pendrak, M.L.; Roberts, D.D.; Durell, S.R.; et al. Programmable multivalent display of receptor ligands using peptide nucleic acid nanoscaffolds. Nat. Commun. 2012, doi:10.1038/ncomms1629.

66. Scheibe, C.; Bujotzek, A.; Dernedde, J.; Weberb, M.; Seitz, O. DNA-programmed spatial screening of carbohydrate-lectin interactions. Chem. Sci. 2011, 2, 770-775. 
67. Sforza, S.; Tedeschi, T.; Corradini, R.; Marchelli, R. Induction of helical handedness and DNA binding properties of peptide nucleic acids (PNAs) with two stereogenic centres. Eur. J. Org. Chem. 2007, 2007, 5879-5885.

68. Avitabile, C.; Moggio, L.; Malgieri, G.; Capasso, D.; Gaetano, S.D.; Saviano, M.; Pedone, C.; Romanelli, A. $\gamma$ sulphate PNA (PNA S): Highly selective DNA binding molecule showing promising antigene activity. PLoS One 2012, 7, e35774.

69. Yeh, J.I.; Boris Shivachev, B.; Rapireddy, S.; Crawford, M.J.; Gil, R.R.; Du, S.; Madrid, M.; Ly, D.H. Crystal structure of chiral $\gamma$ PNA with complementary DNA strand: Insights into the stability and specificity of recognition and conformational preorganization. J. Am. Chem. Soc. 2010, 132, 10717-10727.

70. Crawford, M.J.; Rapireddy, S.; Bahal, R.; Sacui, I.; Ly, D.H. Effect of steric constraint at the $\gamma$-backbone position on the conformations and hybridization properties of PNAs. J. Nucleic Acids 2011, 2011, doi:10.4061/2011/652702.

71. Nielsen, P.E.; Christensen, L. Strand displacement binding of a duplex-forming homopurine PNA to a homopyrimidine duplex DNA target. J. Am. Chem. Soc. 1996, 118, 2287-2288.

72. Zhang, X.; Ishihra, T.; Corey, D.R. Strand invasion by mixed base PNAs and a PNA-peptide chimera. Nucleic Acids Res. 2000, 28, 3332-3338.

73. Smolina, I.V.; Demidov, V.V.; Soldatenkov1, V.A.; Chasovskikh1, S.G.; Frank-Kamenetskii, M.D. End invasion of peptide nucleic acids (PNAs) with mixed-base composition into linear DNA duplexes. Nucleic Acids Res. 2005, 33, e146.

74. Avitabile, C.; Saviano, M.; D’Andrea, L.D.; Bianchi, N.; Fabbri, E.; Brognara, E.; Gambari, R.; Romanelli, A. Targeting pre-miRNA by peptide nucleic acids. Artificial DNA PNA XNA 2012, 3, 88-96.

75. Rapireddy, S.; He, G.; Roy, S.; Armitage, B.A.; Ly, D.H. Strand invasion of mixed-sequence B-DNA by acridine-linked, $\gamma$-peptide nucleic acid ( $\gamma$-PNA). J. Am. Chem. Soc. 2007, 129, 15596-15600.

76. Chenna, V.; Rapireddy, S.; Sahu, B.; Ausin, C.; Pedroso, E.; Ly, D.H. A simple cytosine to G-clamp nucleobase substitution enables chiral $\gamma$-PNAs to invade mixed-sequence double-helical B-form DNA. ChemBioChem 2008, 9, 2388-2391.

77. Rapireddy, S.; Bahal, R.; Ly, D.H. Strand invasion of mixed-sequence, double-helical B-DNA by $\gamma$-peptide nucleic acids containing G-clamp nucleobases under physiological conditions. Biochemistry 2011, 50, 3913-3918.

78. He, G.; Rapireddy, S.; Bahal, R.; Sahu, B.; Ly, D.H. Strand invasion of extended, mixed-sequence B-DNA by $\gamma$ PNAs. J. Am. Chem. Soc. 2009, 131, 12088-12090.

79. Bahal, R.; Sahu, B.; Rapireddy, S.; Lee, C.-M.; Ly, D.H. Sequence-unrestricted, Watson-Crick recognition of double helical B-DNA by (R)-MiniPEG- $\gamma$ PNAs. ChemBioChem 2012, 13, 56-60.

80. Manicardi, A.; Fabbri, E.; Tedeschi, T.; Sforza, S.; Nicoletta Bianchi, N.; Brognara, E.; Gambari, R.; Marchelli, R.; Corradini, R. Cellular uptakes, biostabilities and anti-miR-210 activities of chiral arginine-PNAs in leukaemic K562 cells. ChemBioChem 2012, 13, 1327-1337.

81. Manizardi, A.; Calabretta, A.; Bencivenni, M.; Tedeschi, T.; Sforza, S.; Corradini, R.; Marchelli, R. Affinity and selectivity of C2- and C5-substituted "chiral-box" PNA in solution and on microarrays. Chirality 2010, 22, E161-E171. 
82. Sforza, S.; Tedeschi, T.; Calabretta, A.; Corradini, R.; Camerin, C.; Tonelli, R.; Pession, A.; Marchelli, R. A peptide nucleic acid embedding a pseudopeptide nuclear localization sequence in the backbone behaves as a peptide mimic. Eur. J. Org. Chem. 2010, 2010, 2441-2444.

83. Mitra, R.; Ganesh, K.N. PNAs grafted with $(\alpha / \gamma, R / S)$-aminomethylene pendants: Regio and stereo specific effects on DNA binding and improved cell uptake. Chem. Commun. 2011, 47, 1198-1200.

84. Mitra, R.; Ganesh, K.N. Aminomethylene peptide nucleic acid (am-PNA): Synthesis, regio/stereospecific DNA binding, and differential cell uptake of $(\alpha / \gamma, R / S)$ am-PNA analogues. J. Org. Chem. 2012, 77, 5696-5704.

85. Myers, M.C.; Witschi, M.A.; Larionova, N.V.; Frank, J.M.; Haynes, R.D.; Hara, T.; Grajkowski, A.; Appella, D.H. A cyclopentane conformational restraint for a peptide nucleic acid: Design, asymmetric synthesis, and improved binding affinity to DNA and RNA. Org. Lett. 2003, 5, 2695-2698.

86. Pokorski, J.K.; Witschi, M.A.; Purnell, B.L.; Appella, D.H. (S,S)-trans-Cyclopentane-constrained peptide nucleic acids. A general backbone modification that improves binding affinity and sequence specificity. J. Am. Chem. Soc. 2004, 126, 15067-15073.

87. Pokorski, J.K.; Myers, M.C.; Appella, D.H. Cyclopropane PNA: Observable triplex melting in a PNA constrained with a 3-membered ring. Tetrahedron Lett. 2005, 46, 915-917.

88. Govindaraju, T.; Kumar, V.A.; Ganesh, K.N. cis-Cyclopentyl PNA ( $c p$ PNA) as constrained chiral PNA analogues: Stereochemical dependence of DNA/RNA hybridiation. Chem. Commun. 2004, 860-861.

89. Govindaraju, T.; Kumar, V.A.; Ganesh, K.N. (SR/RS)-Cyclohexanyl PNAs: Conformationally preorganized PNA analogues with unprecedented preference for duplex formation with RNA. J. Am. Chem. Soc. 2005, 127, 4144-4145.

90. Lagriffoule, P.; Wittung, P.; Ericksson, M.; Jensen, D.K.; Norden, B.; Buchardt, O.; Nielsen, P.E. Peptide nucleic acids with a conformationally constrained chiral cyclohexyl-derived backbone. Chem. Eur. J. 1997, 3, 912-919.

91. Bregant, S.; Burlina, F.; Vaissermann, J.; Chassaing, G. Synthesis and hybridization properties of thiazolidine PNAs. Eur. J. Org. Chem. 2001, 2001, 3285-3294.

92. Bregant, S.; Burlina, F.; Chassaing, G. New thiazane and thiazolidine PNA monomers: Synthesis, incorporation into PNAs and hybridization studies. Bioorg. Med. Chem. Lett. 2002, 12, 1047-1050.

93. Sugiyama, T.; Imamura, Y.; Demizu, Y.; Kurihara, M.; Takano, M.; Kittaka, A. $\beta$-PNA: Peptide nucleic acid (PNA) with a chiral center at the $\beta$-position of the PNA backbone. Bioorg. Med. Chem. Lett. 2011, 21, 7317-7320.

Sample Availability: Not available.

(C) 2013 by the authors; licensee MDPI, Basel, Switzerland. This article is an open access article distributed under the terms and conditions of the Creative Commons Attribution license (http://creativecommons.org/licenses/by/3.0/). 